\title{
Modulation of ionospheric outflow ions by EMIC waves in the dayside outer magnetosphere
}

\author{
Chen Shi, Jinsong Zhao, Chaoyan Huang, Tieyan Wang \\ and Malcolm W. Dunlop
}

\section{Published version information}

Citation: C Shi et al. 'Modulation of ionospheric outflow ions by EMIC waves in the dayside outer magnetosphere.' Physics of Plasmas, vol. 27, no. 3 (2020): 032902.

DOI: $\underline{10.1063 / 1.5142686}$

This article may be downloaded for personal use only. Any other use requires prior permission of the author and AIP Publishing.

This version is made available in accordance with publisher policies. Please cite only the published version using the reference above. This is the citation assigned by the publisher at the time of issuing the APV. Please check the publisher's website for any updates. 


\section{Modulation of ionospheric outflow ions by EMIC waves in the dayside outer magnetosphere}

Cite as: Phys. Plasmas 27, 032902 (2020); https://doi.org/10.1063/1.5142686

Submitted: 17 December 2019 . Accepted: 13 February 2020 . Published Online: 13 March 2020

Chen Shi ${ }^{(D)}$, Jinsong Zhao (D), Chaoyan Huang (D), Tieyan Wang ${ }^{(D)}$, and Malcolm W. Dunlop (iD)
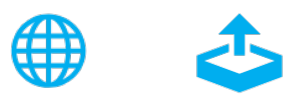

View Online

Export Citation

\section{ARTICLES YOU MAY BE INTERESTED IN}

Generation of kinetic Alfvén wave and whistler waves by parametric decay of high power laser in laser-plasma interaction

Physics of Plasmas 27, 032111 (2020); https://doi.org/10.1063/1.5139302

A closer look at turbulence spreading: How bistability admits intermittent, propagating turbulence fronts

Physics of Plasmas 27, 032303 (2020); https://doi.org/10.1063/1.5138129

Impact of stalk on directly driven inertial confinement fusion implosions

Physics of Plasmas 27, 032704 (2020); https://doi.org/10.1063/1.5141607

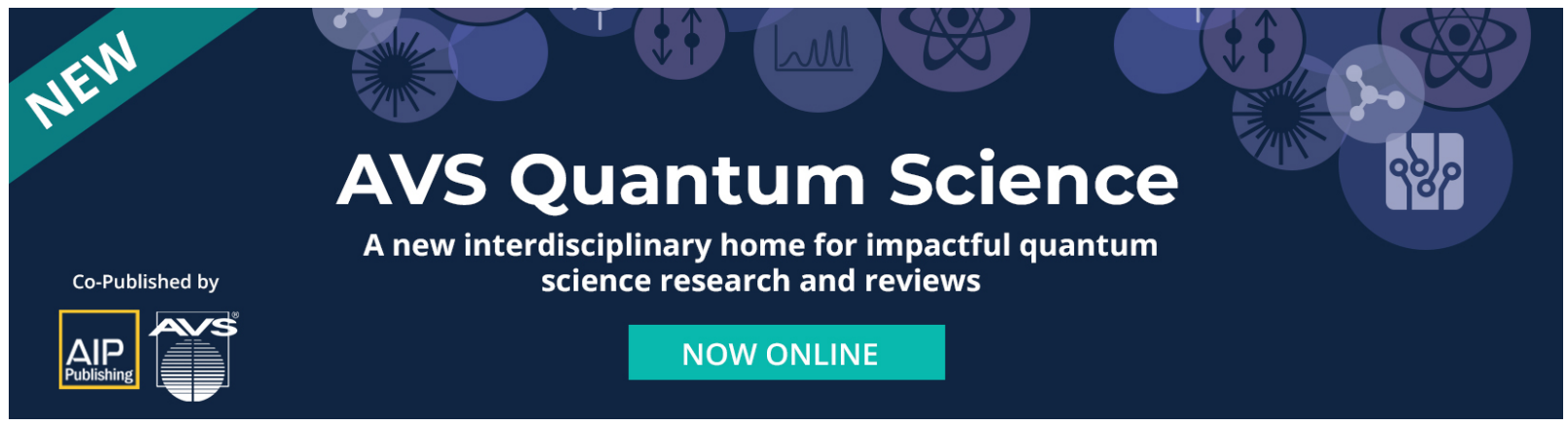




\title{
Modulation of ionospheric outflow ions by EMIC waves in the dayside outer magnetosphere
}

\author{
Cite as: Phys. Plasmas 27, 032902 (2020); doi: 10.1063/1.5142686 \\ Submitted: 17 December 2019 - Accepted: 13 February 2020 . \\ Published Online: 13 March 2020
}

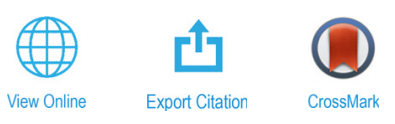

Chen Shi, ${ }^{1,2}$ (D) Jinsong Zhao, ${ }^{2, a)}$ (D) Chaoyan Huang, ${ }^{1}$ (D) Tieyan Wang, ${ }^{3}$ (D) and Malcolm W. Dunlop ${ }^{3,4}$ (D)

\begin{abstract}
AFFILIATIONS
${ }^{7}$ College of Astronautics, Nanjing University of Aeronautics and Astronautics, Nanjing 210016, China

${ }^{2}$ Key Laboratory of Planetary Sciences, Purple Mountain Observatory, Chinese Academy of Sciences, Nanjing 210033, China

${ }^{3}$ RAL Space, STFC, Oxfordshire OX11 OQX, United Kingdom

${ }^{4}$ School of Space and Environment, Beihang University, Beijing 100191, China
\end{abstract}

a) Author to whom correspondence should be addressed: js_zhao@pmo.ac.cn

\begin{abstract}
Cold ions of the ionospheric origin mainly contribute to the ion population in the Earth's magnetosphere. These cold ions can be modulated by Pc5 ultralow frequency waves or wake electric fields in the dayside outer magnetosphere, through which their energy can increase to hundreds of eV. Using measurements of Magnetospheric Multiscale mission, this paper reports a new finding of the cold ion modulation process, occurring at a timescale of several seconds. This modulation is identified to be mainly controlled by large-amplitude electromagnetic ion cyclotron (EMIC) waves through the wave-induced electric field drift. This study also gives distinct observational features in the cold ion modulation processes associated with EMIC waves and wake electric fields.
\end{abstract}

Published under license by AIP Publishing. https://doi.org/10.1063/1.5142686

\section{INTRODUCTION}

Cold ions are mainly responsible for the ion density and ion flux in the Earth's magnetosphere. ${ }^{1}$ These cold ions can escape from the ionosphere in the polar cap and the equator and then enter the Earth's magnetotail and magnetopause. ${ }^{2-7}$ Their dynamics have attracted much attention in the space physics community. For example, as the cold ion gyroradius is comparable with the electron inertial length, cold ions can considerably affect the dynamics in the magnetic reconnection near the boundary of the outer magnetosphere ${ }^{8-16}$ and can also modify the Hall physics therein. ${ }^{17,18}$

Due to the sunlit-induced photoelectron emission in the dayside outer magnetosphere, the spacecraft is positively charged to a few to tens of volts, and consequently, the cold ions (a few eV) are prevented from reaching the onboard detectors. ${ }^{1}$ However, an in situ spacecraft often measures ions with energies around hundreds of $\mathrm{eV}$ in the outer magnetosphere. Moreover, these cold ions sometimes exhibit periodic variations in the ion energy spectrogram. ${ }^{19-21}$ The modulation of cold ions is caused by ultralow frequency (ULF) waves in the Pc5 band $(\sim \mathrm{a}$ few $\mathrm{mHz}){ }^{19-22}$ ULF waves are common in the Earth's magnetosphere and can efficiently transfer energy with energized particles. ${ }^{23-31}$ Recently, the ULF wave-induced cold ion enhancements are clearly explored from Magnetospheric Multiscale (MMS) mission. ${ }^{20,21}$ Through the $\boldsymbol{E} \times \boldsymbol{B}$ drift resulting from ULF waves, low-energy cold ions (a few eV) are converted to ions with energy exceeding the minimum energy threshold of the MMS plasma instrument, which induces these hidden cold ions reaching the onboard detector. ${ }^{20,21}$ Also, ULF waves can naturally produce periodic variations of energy of cold ions due to their electric fluctuations. Furthermore, besides the $\boldsymbol{E} \times \boldsymbol{B}$ drift, Liu et $a .^{21}$ found that the ULF wave-induced polarization drift can dominate the modulation of cold heavy ions (e.g., $\mathrm{O}^{+}$), where the energy resulting from the polarization drift can be 9 times larger than the energy associated with the $\boldsymbol{E} \times \boldsymbol{B}$ drift.

In this study, using data from the MMS spacecraft, we find a new modulation behavior of cold ions in the dayside outer magnetosphere, that is, ions with periodic variations around several seconds as seen in the energy spectrogram. This timescale is much smaller than the timescale in the modulation of cold ions relating to Pc5 ULF waves. ${ }^{20,21}$ Accompanying cold ions, there exists large-amplitude electromagnetic ion cyclotron (EMIC) waves having a frequency of $\sim 0.2 \mathrm{~Hz}$. Through analyzing the dynamical relationship between EMIC waves and cold ions, we propose that the EMIC wave-induced the $\boldsymbol{E} \times \boldsymbol{B}$ drift is mainly responsible for such short-timescale cold ion modulation.

\section{DATA SET}

The cold ion and wave activity are analyzed by using plasma and electromagnetic data from the MMS mission. The Fast Plasma 
Investigation (FPI) provides plasma data with a temporal resolution of $4.5 \mathrm{~s}$ in fast mode and $150 \mathrm{~ms}$ for ions and $30 \mathrm{~ms}$ for electrons in burst mode. ${ }^{32}$ Since the Dual Ion Spectrometer (DIS) in FPI cannot distinguish protons from other kinds of ion species, ions are assumed to be protons in our analysis. Magnetic field data from the FluxGate Magnetometer (FGM) have a temporal resolution of 16 samples/s in survey mode, ${ }^{33}$ and the Electric Double Probes (EDPs) give the electric field data with a sample rate of $32 \mathrm{~Hz}^{34,35}$

\section{EVENT OVERVIEW}

Figure 1 shows an overview of the event on 7 January 2019. Figure 1(a) gives the ion differential energy flux $E_{i}$, and Fig. 1(b) presents the magnetic field $\boldsymbol{B}_{\mathrm{GSE}}$ in Geocentric Solar Ecliptic (GSE) coordinates. From Figs. 1(a) and 1(b), we find that MMS 1 stays in the Earth's magnetosheath during a time interval of $\sim$ 19:00:00UT $-19: 03: 00 \mathrm{UT}$ and a short-time interval of $\sim$ 19:21:50UT - 19:22:10UT, when $E_{i}$ is enhanced near $1 \mathrm{keV}$, and magnetic fields are strongly disturbed. While MMS 1 moves into the magnetosphere, both high-energy $\left(E_{i} \geqslant 10 \mathrm{keV}\right)$ and low-energy $\left(E_{i} \sim 1-100 \mathrm{eV}\right)$ components are found in $E_{i}$. Moreover, there are magnetic fluctuations having a period of $\sim 5 \mathrm{~min}$, which correspond to Pc5 ULF waves. The interaction between ULF waves and cold ions has been recently studied in Refs. 20 and 21. Here, clear evidence for ULF wave-modulated cold ions is illustrated in Figs. 1(c) $-1(\mathrm{~g})$, which provides a zoomed view of 20:28:00UT - 20:43:50UT. Figure 1(c) presents ion and electron number densities using the fast mode data of FPI. The ion number density increases from $\sim 1 \mathrm{~cm}^{-3}$ up to $\sim 2-3 \mathrm{~cm}^{-3}$, whereas the electron number density remains stable $\backsim 1 \mathrm{~cm}^{-3}$. This ion number density enhancement agrees with the appearance of cold ions with $E_{i} \sim 1-100 \mathrm{eV}$ as shown in Fig. 1(d). From Figs. 1(e)-1(g), we find ULF waves with the magnetic field amplitude $\sim 4 \mathrm{nT}$ and the electric field amplitude $\sim 3 \mathrm{mV} / \mathrm{m}$. To show the cold ion modulation by ULF waves, the $\boldsymbol{E} \times \boldsymbol{B}$ drift ion energy $W_{E}=m_{p} V_{E}^{2} / 2$ and the total drift energy $W_{T}=m_{p}\left(V_{E}+V_{P}\right)^{2} / 2$ are also overlaid in Fig. 1(d), where $\boldsymbol{V}_{E}=\boldsymbol{E} \times \boldsymbol{B} / B^{2}$ and $\boldsymbol{V}_{P}=m_{p} d_{t} \boldsymbol{E} / e B^{2}$ are the electric field drift and the polarization drift, respectively. Here, $V_{E}$ and $V_{P}$ are sampled at the temporal resolution of the fast mode of FPI. $W_{E}$ is nearly as same as $W_{T}$, indicating that $\boldsymbol{V}_{E}$ is the main contribution to the cold ion modulation. Comparing $W_{E}$ to $E_{i}$, we find that $W_{E}$ closely follows the variation of the cold ion energy. Hence, we conclude that these cold ions are modulated by ULF waves. 20,21

Figure 2 presents the ion energy spectra in different directions from measurements of FPI/DIS. The spectra are made in the Despun Body Coordinate System (DBCS), which nearly match with GSE coordinates due to the small angle between the positive spin axis of MMS and the ecliptic normal around $3^{\circ}$. In Fig. 2, the differential energy flux $E_{i}$ in each energy bin is averaged over particles with the DBCS flow direction within $45^{\circ}$ of each axis. Comparing Figs. 2(a) and 2(b), the $E_{i}$ values of cold ions (below $100 \mathrm{eV}$ ) near $+\mathrm{x}$ and $-\mathrm{x}$ are asymmetric, and this asymmetry is nearly in agreement with the appearance of $V_{E}$ at $+\mathrm{x}$ and $-\mathrm{x}$ directions in Fig. 2(c). Also, the asymmetry of $E_{i}$ near $+y /-y$ [Figs. 2(d) and 2(e)] and near $+z /-z$ [Figs. 2(g) and 2(h)] is nearly consistent with variances of $V_{E}$ at $+y /-y$ [Fig. 2(f)] and $+z /-z$ [Fig. 2(i)]. Therefore, the modulation of cold ions by ULF waves is again identified by Fig. 2 .
Besides Pc5 ( $\backsim 5 \mathrm{~min})$ ULF waves, cold ions are also observed in accompany with EMIC waves. Figure 3 presents the polarization analysis by using the singular value decomposition method. ${ }^{36}$ From top to bottom panels, we give the power spectral density of the perpendicular magnetic field, the power spectral density of the perpendicular electric field, the wave normal angle $(\theta)$, the degree of polarization (DOP), the ellipticity, and the parallel Poynting flux $S_{\|}$normalized by $|S|$. In Fig. 3 , the proton cyclotron frequency $f_{\mathrm{cp}}$ and the helium cyclotron frequency $f_{\mathrm{cH}_{\mathrm{e}}^{+}}$are overlaid. Clear signatures of quasi-monochromatic waves between 0.1 and $0.5 \mathrm{~Hz}\left(H^{+}\right.$-band waves) can be seen. These waves have small normal angles $\left(\lessgtr 30^{\circ}\right)$ and strong DOP $(\gtrsim 0.7)$. Moreover, most of the waves have the ellipticity smaller than -0.7 and $S_{\|}<0$. Therefore, these features indicate the presence of EMIC waves propagating against the magnetic field.

The MMS has high-temporal resolution (burst mode) measurements during 20:39:24UT - 20:41:23UT (the region between two vertical dashed lines in Figs. 1-3), when EMIC waves have considerable electromagnetic fluctuations, and these measurements are in favor of studying the modulation of cold ions by EMIC waves.

\section{MODULATION OF IONOSPHERIC OUTFLOW IONS BY EMIC WAVES}

More detailed properties of EMIC waves are presented in Fig. 4, where Figs. 4(a)-4(d) plot $\boldsymbol{B}_{\mathrm{GSE}}$ and $\boldsymbol{E}_{\mathrm{GSE}}$ in GSE coordinates during the burst time interval of 20:39:24UT-20:41:23UT. Before 20:40:50UT, there exist quasi-monochromic EMIC waves with the period of approximately $5 \mathrm{~s}$ and having the maximum strength at $\sim 20: 40: 30 \mathrm{UT}$. The peak-to-peak amplitudes are $\delta B \backsim 4 \mathrm{nT}$ and $\delta E \backsim 3$ $\mathrm{mV} / \mathrm{m}$. In comparison to the ambient magnetic field $B_{0} \backsim 47 \mathrm{nT}$, the relative magnetic amplitude is nearly 0.09. Note that during 20:40:25UT - 20:40:35UT when EMIC waves are the strongest, the distribution of $E_{z}$ contains several dipolar structures where the $E_{z}$ direction rapidly changes [Fig. 4(d)]. In addition, high-frequency electrostatic fluctuations between $f_{\text {cp }}$ and $0.1 f_{\text {ce }}$ are also observed.

Figures 4(e)-4(g) present the ion velocity $\boldsymbol{V}_{\text {iGSE }}$ in GSE coordinates from the burst mode data of FPI. The $\boldsymbol{E} \times \boldsymbol{B}$ drift velocity $\boldsymbol{V}_{E}$ (sampled at the temporal resolution of the burst mode of FPI) is also overlaid in Figs. 4(e)-4(g). $\boldsymbol{V}_{\boldsymbol{E}}$ is in good agreement with $\boldsymbol{V}_{\mathrm{iGSE}}$, especially for the $\boldsymbol{E} \times \boldsymbol{B}$ drift velocity resulting from EMIC waves. Therefore, we conclude that the short-timescale ion velocity fluctuation is dominated by the EMIC wave-induced $\boldsymbol{E} \times \boldsymbol{B}$ drift.

Figures $4(\mathrm{~h})-4(\mathrm{k})$ further present the time series of magnetic field fluctuations $\boldsymbol{B}_{\perp}$ and ion velocity fluctuations $\boldsymbol{V}_{i \perp}$ perpendicular to the background magnetic field $\boldsymbol{B}_{0}$. To obtain $\boldsymbol{B}_{\perp}$ and $\boldsymbol{V}_{i \perp}$, we choose $\boldsymbol{B}_{0}$ through averaging the magnetic field over $20 \mathrm{~s}$ and then transform $\boldsymbol{B}_{\mathrm{GSE}}$ and $\boldsymbol{V}_{\mathrm{iGSE}}$ to the field-aligned coordinates (FAC). From the distribution of $\boldsymbol{B}_{\perp}$ in Fig. 4(h), we see that the phase $B_{\perp 1}$ is nearly behind of $B_{\perp 2}$ by $\pi / 2$, indicating the left-hand polarization for EMIC waves. For the strong EMIC waves in $\sim 20: 40: 20 \mathrm{UT}-20: 40: 35 \mathrm{UT}$, the phase difference between $B_{\perp 1}$ and $B_{\perp 2}$ is near 0 or $\pi$, and the amplitude of $B_{\perp 1}$ is much smaller than that of $B_{\perp 2}$. The phase difference of $V_{\perp 1}$ and $V_{\perp 2}$ in Fig. 4(i) nearly retains $\pi / 2$ during the whole EMIC time interval. Moreover, for the strongest EMIC waves, the amplitude of $V_{\perp 1}$ is smaller than that of $V_{\perp 2}$. Furthermore, Figs. $4(\mathrm{j})$ and $4(\mathrm{k})$ compare $\boldsymbol{B}_{\perp}$ (normalized by $B_{0}$ ) to $V_{i \perp}$ (normalized by the Alfvén speed $V_{A}$ ). In the EMIC wave time interval, we find $\boldsymbol{B}_{\perp} / B_{0} \simeq \boldsymbol{V}_{i \perp} / V_{A}$. This positive correlation relation indicates the EMIC wave propagating 


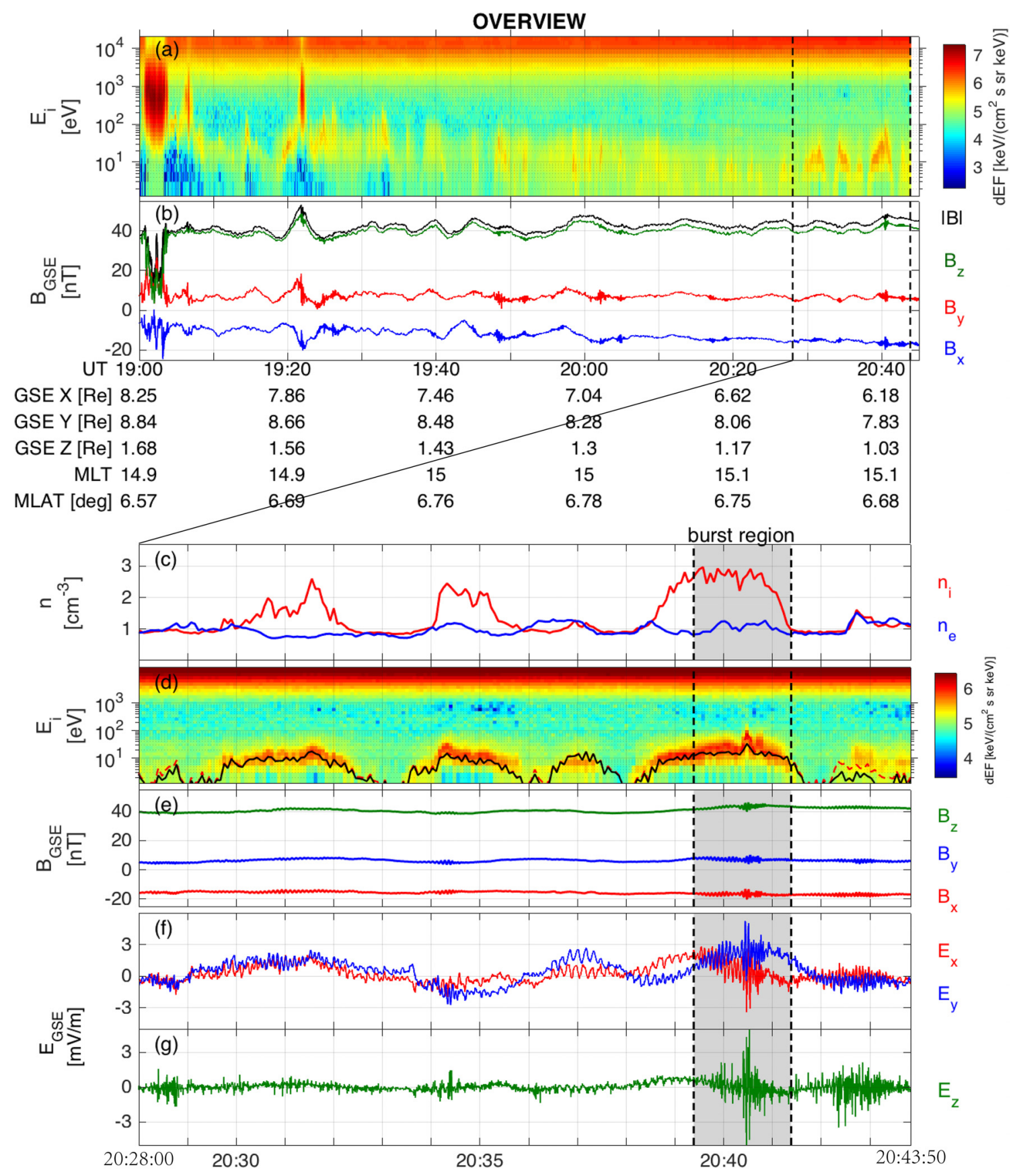

FIG. 1. Overview of the cold ion event as observed by MMS 1 on 7 January 2019. (a) and (b) lon energy spectrogram and magnetic field during 19:00:00UT - 20:45:00UT. (c) - (f) Plasma and electromagnetic field observations in the interval from 20:28:00UT to 20:43:50UT. (c) lon and electron number density. (d) lon energy spectrogram, where the black solid and red dashed lines represent the $\boldsymbol{E} \times \boldsymbol{B}$ drift ion energy $W_{E}$ and the total drift energy $W_{T}$. (e) Magnetic field in GSE coordinates. (f) and (g) Electric field in GSE coordinates. The time interval between the two vertical dashed lines in panels $(\mathrm{c})-(\mathrm{g})$ contains burst mode data.

antiparallel to $\boldsymbol{B}_{0},{ }^{37,38}$ which is consistent with the Poynting flux direction shown in Fig. 2(f).

Figures 4(1) and 4(m) present power spectral densities (PSDs) of $\boldsymbol{B}$ and $\boldsymbol{E}$ using Welch's method. ${ }^{39}$ Both PSDs of $\boldsymbol{B}_{\perp}$ and $\boldsymbol{E}_{\perp}$ are larger than the corresponding PSDs of $\mathrm{B}_{\|}$and $\mathrm{E}_{\|}$in a frequency range of $0.1-0.5 \mathrm{~Hz}$. The EMIC wave frequency is centered around $f \sim 0.2$ $\mathrm{Hz}$, which is nearly 3 times smaller than the averaged proton cyclotron frequency $f_{c p} \sim 0.7 \mathrm{~Hz}$. It should be noted that since the Alfvén speed 


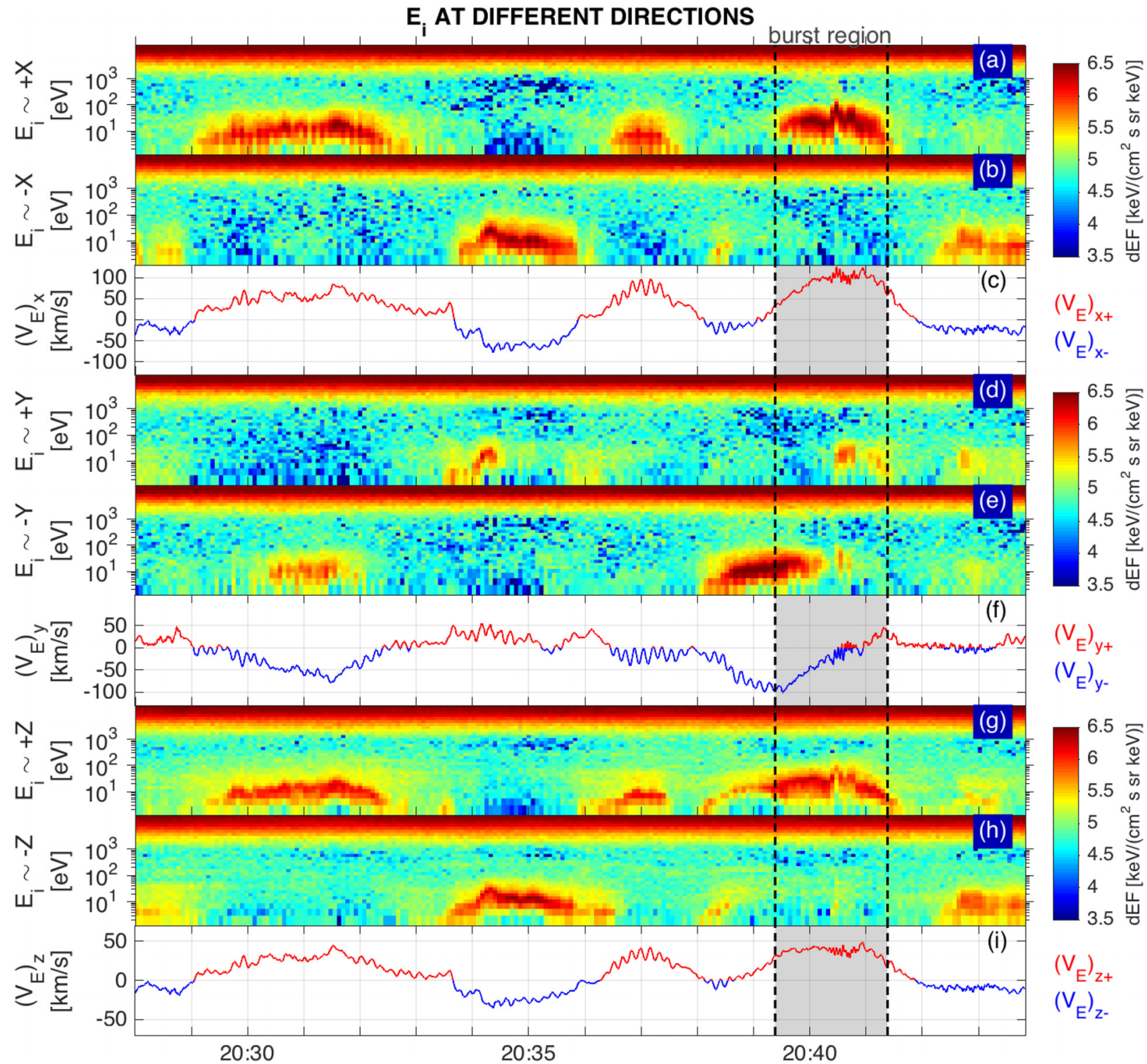

FIG. 2. Ion energy spectra $E_{i}$ at different directions: (a) and (b) $E_{i}$ near $+x$ and $-x$ directions in Despun Body Coordinate System (DBCS); (d) and (e) $E_{i}$ near $+y$ and $-y$ directions in DBCS; and (g) and ( $h$ ) $E_{i}$ near $+z$ and $-z$ directions in DBCS. Electric field drift velocities $V_{E}$ at different directions: (c) $x$, (f) $y$, and (i) $z$ in GSE coordinates. The red and blue lines in panels (c), (f), and (i) represent the drift velocity along and against each axis. Since the positive spin axis of MMS retains within around $3^{\circ}$ from ecliptic normal, DBCS is nearly in accordance with GSE coordinates.

$V_{A}=B_{0} / \sqrt{\mu_{0} m_{i} n} \simeq 458 \mathrm{~km} / \mathrm{s}$, as computed from $B_{0} \simeq 47 \mathrm{nT}$ and $n=5 \mathrm{~cm}^{-3}$, is much larger than the ion bulk flow speed $V_{\text {flow }} \simeq 47 \mathrm{~km} / \mathrm{s}$, the Doppler shift is negligible, and the wave frequency $f \sim 0.2 \mathrm{~Hz}$ in the spacecraft frame is nearly the same as that in the plasma frame.

Due to the $V_{E}$ induced by ULF and EMIC waves, the ion energy can exceed the lowest energy channel in the FPI instrument. The details of the short-timescale modulation of cold ions by EMIC waves, based on burst mode data, are shown in Fig. 5. Figure 5(a) presents ion and electron number densities, where the ion number density behaves as a periodic variation between $n_{i} \sim 1 \mathrm{~cm}^{-3}$ and $\sim 5 \mathrm{~cm}^{-3}$, but the electron number density nearly remains constant $n_{e} \sim 1 \mathrm{~cm}^{-3}$. Comparing Fig. 5(a) with Fig. 1(c), we see that the ion density measured in the fast mode $\left(\sim 1-3 \mathrm{~cm}^{-3}\right)$ actually underestimates the cold ion density. Figure 5(b) shows the ion energy spectrogram and the $\boldsymbol{E} \times \boldsymbol{B}$ drift energy $W_{E}$. The cold ion energy $E_{i}$ is consistent with the theoretical prediction of $W_{E}$. The modulation of cold ions is explored by Figs. $5(\mathrm{c})-5(\mathrm{f})$ in detail, which shows the ion pitch angle spectrogram for $2.2 \mathrm{eV} \leq E_{i} \leq 153.4 \mathrm{eV}$ [Fig. 5(c)], the normalized differences $\frac{\mathrm{PSD}_{\text {para }}-\mathrm{PSD}_{\text {perp }}}{\mathrm{PSD}_{\text {para }}+\mathrm{PSD}_{\text {perp }}}$ between the ion parallel and perpendicular PSDs 


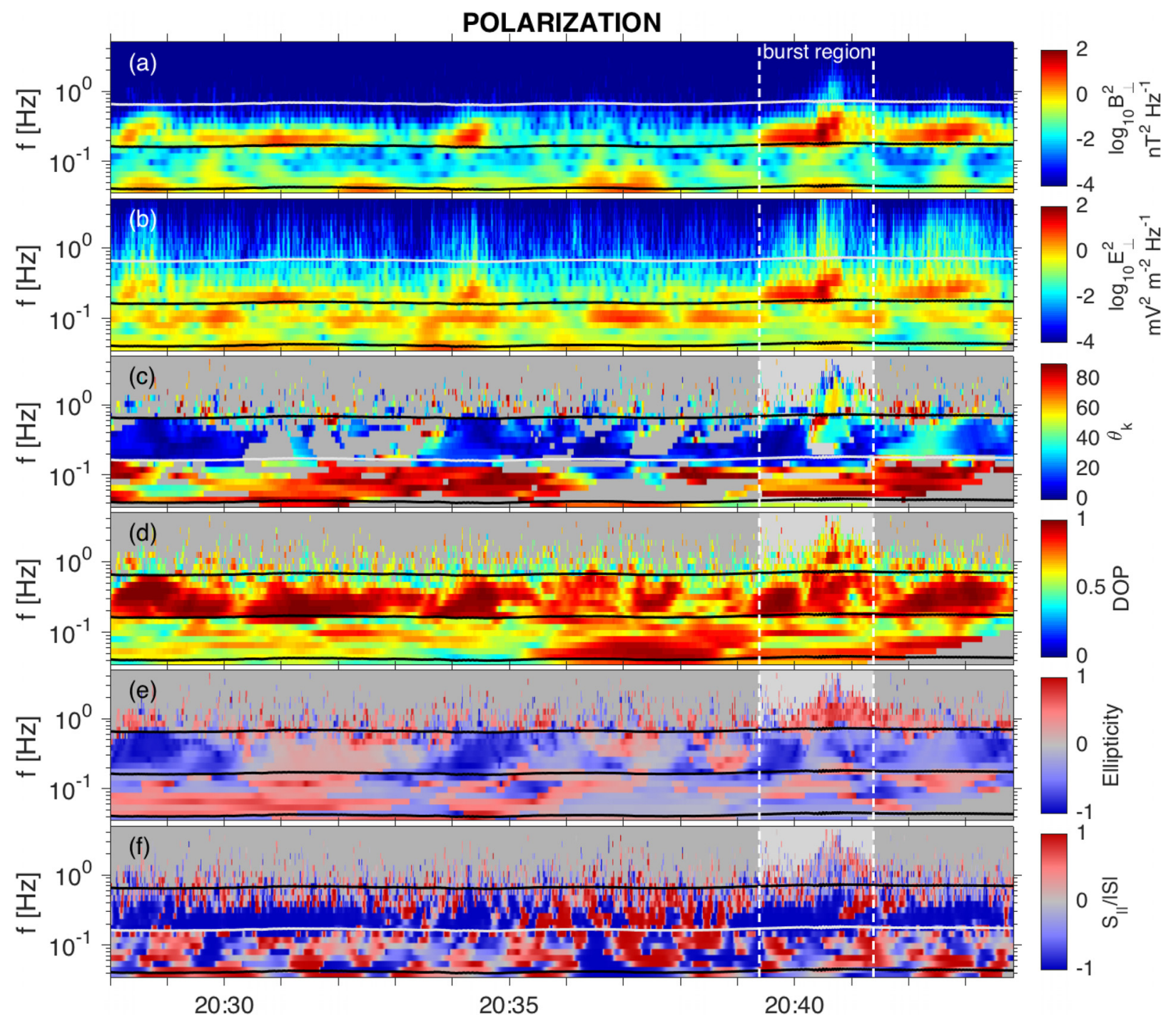

FIG. 3. Polarization analysis. (a) Power spectral density of the perpendicular magnetic field. (b) Power spectral density of the perpendicular electric field. (c) Wave normal angle $(\theta)$. (d) Degree of polarization (DOP). (e) Ellipticity. (f) The parallel Poynting flux $S_{\|}$normalized by $|S|$. Three solid lines represent the proton cyclotron $f_{\mathrm{cp}}$, helium cyclotron $f_{\mathrm{cH}_{\mathrm{e}}^{+}}$, and oxygen cyclotron $f_{\mathrm{cO}^{+}}$frequencies, respectively.

[Fig. 5(d)], the normalized differences $\frac{\mathrm{PSD}_{\text {anti }}-\mathrm{PSD}_{\text {perp }}}{\mathrm{PSD}_{\text {anti }}+\mathrm{PSD}_{\text {perp }}}$ between the ion antiparallel and perpendicular PSDs [Fig. 5(e)], and the distribution of the magnitude of the $\boldsymbol{E} \times \boldsymbol{B}$ drift velocity $\left|V_{E}\right|$ [Fig. 5(f)]. Figures 5(c)-5(f) show that at the minima of $\left|V_{E}\right|$ induced by EMIC waves (vertical dashed lines), both parallel and antiparallel PSDs are larger than perpendicular PSDs, indicating that cold ions come from the ionospheric outflow. ${ }^{21}$ At the times of the maxima of $\left|V_{E}\right|$, the pitch angle of cold ions is around $90^{\circ}$, which corresponds to the position of the strongest $\boldsymbol{E} \times \boldsymbol{B}$ drift.

Figure 6 shows the ion energy spectrum $E_{i}$ in different directions during the burst time interval. It explores the asymmetric distribution of $E_{i}$ at a short timescale of $\sim 5 \mathrm{~s}$. Similarly, the asymmetric $E_{i}$ is consistent with the variance of the $\boldsymbol{E} \times \boldsymbol{B}$ drift velocity at different directions. Therefore, we demonstrate again the modulation of cold ions by EMIC waves.

\section{DISCUSSION AND SUMMARY}

Based on the MMS measurements of high resolution plasma and field data, this paper reports for the first time the modulation of cold ions by EMIC waves. The $\boldsymbol{E} \times \boldsymbol{B}$ drift of EMIC waves can increase the energy of cold ions up to $E_{i} \sim 100 \mathrm{eV}$ and consequently make them detectable by the onboard plasma instrument. Due to the EMIC wave-induced $\boldsymbol{E} \times \boldsymbol{B}$ drift, the energy of cold ions has periodic variations at a shorttimescale of $\sim 5 \mathrm{~s}$. Moreover, our results indicate the drift of cold ions is dominated by $\boldsymbol{E} \times \boldsymbol{B}$ drift instead of the polarization and diamagnetic drifts. The polarization drift becomes important as the parallel 
B, E, AND V DURING BURST TIME INTERVAL

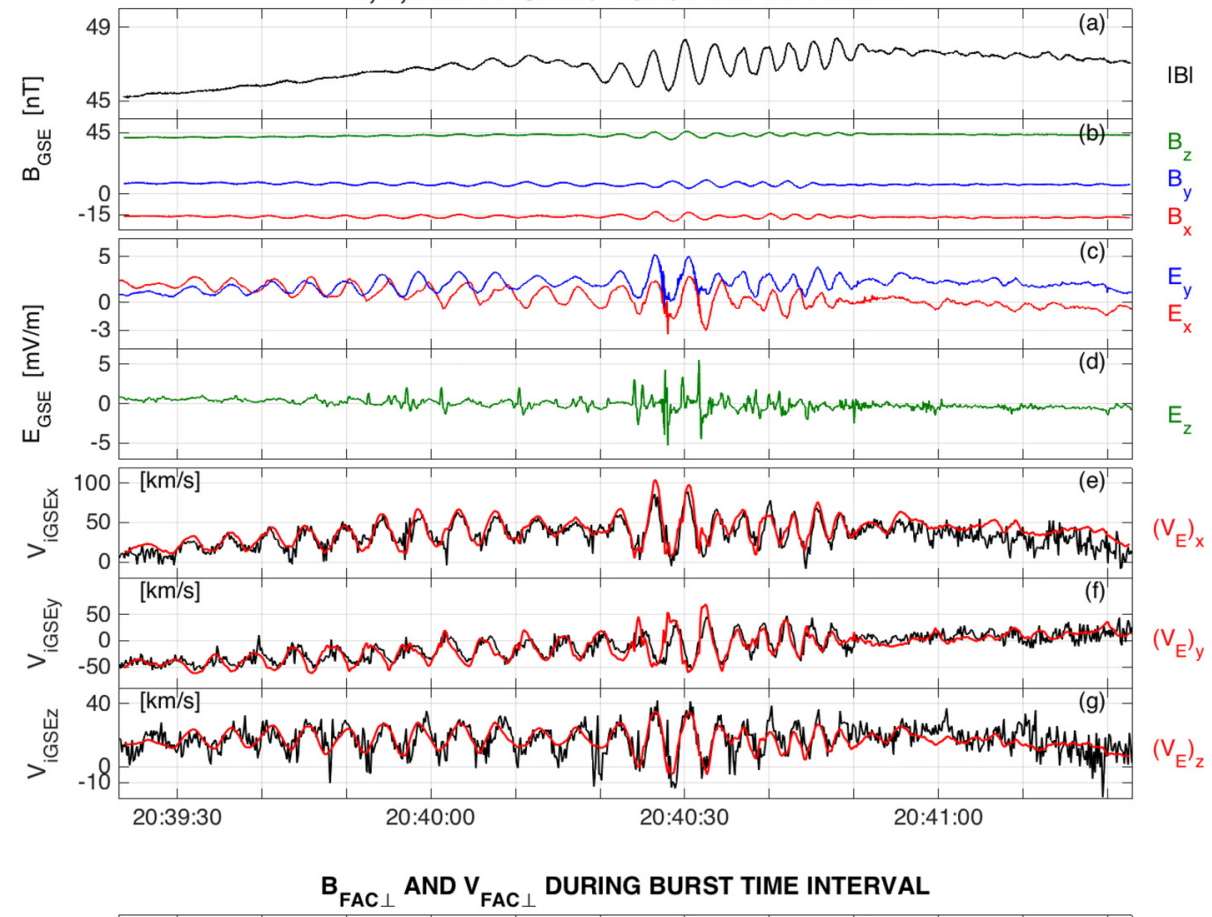

(i)
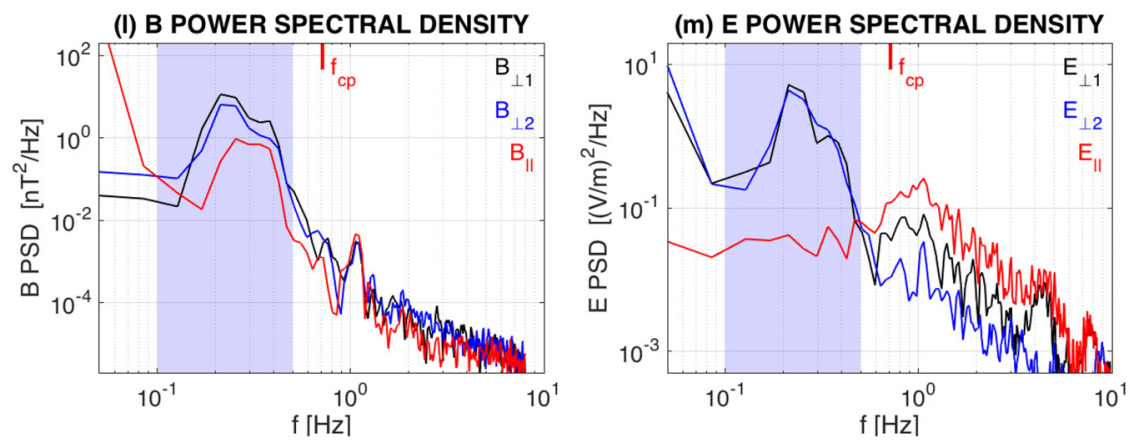

FIG. 4. (a)-(g) Electromagnetic field and ion velocity during the burst time interval of 20:39:24UT - 20:41:23UT. (I) and (m) Power spectral densities of magnetic and electric fields. (a) The total magnetic field $|B|$. (b) Magnetic field $\boldsymbol{B}_{G S E}$ in GSE coordinates. (c) and (d) Electric field $\boldsymbol{E}_{\mathrm{GSE}}$ in GSE coordinates. (e), (f), and (g) lon velocity $V_{\text {iGSE }}$ in GSE coordinates, where the $\boldsymbol{E} \times \boldsymbol{B}$ drift velocity $\boldsymbol{V}_{E}$ is overlaid. (h) Perpendicular magnetic field components $\boldsymbol{B}_{\perp}$ in field-aligned coordinates (FAC) coordinates. (i) Perpendicular ion velocity components $V_{i \perp}$ in FAC coordinates. (j) and $(k)$ Correlation relation between $\boldsymbol{B}_{\perp}$ and $\boldsymbol{V}_{i \perp}$ during the burst time interval. (I) $\boldsymbol{B}$ power spectral density. (m) $\boldsymbol{E}$ power spectral density. $\boldsymbol{B}_{\perp}$ and $\boldsymbol{V}_{i \perp}$ fluctuations are filtered in the range of $0.1 \mathrm{~Hz}-0.5 \mathrm{~Hz}$. All plasma data come from the burst mode data of FPI. wavelength approaches the ion inertial length $\lambda_{i}=\sqrt{m_{p} / \mu_{0} n e^{2}}$ $\simeq 9.5 \mathrm{~km}$, where the plasma density is given as $n=5 \mathrm{~cm}^{-3}$. The diamagnetic drift takes part in the wave dynamics as the perpendicular wavelength is of the order of the ion gyroradius or the finite ion gyroradius. In our event, the ion gyroradius $\rho_{i}$ for cold ions $\left(E_{i} \sim 1-100 \mathrm{eV}\right)$ is nearly $3.1-31 \mathrm{~km}$, and the finite ion gyroradius $\rho_{s}$ at an electron temperature $T_{e} \sim 389 \mathrm{eV}$ is around $62 \mathrm{~km}$, where $T_{e}$ is the averaged electron temperature in the burst 


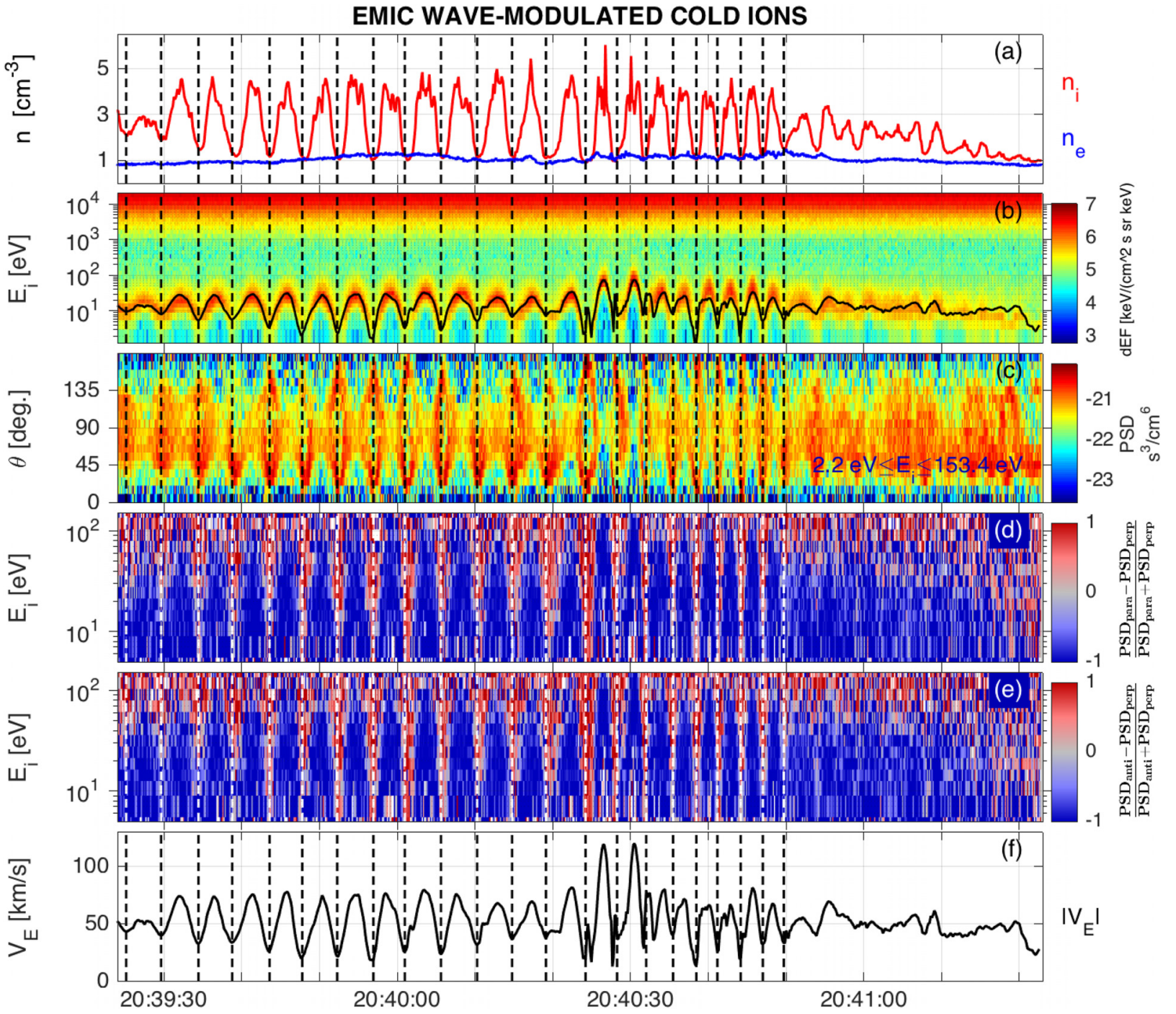

FIG. 5. Modulation of cold ions by EMIC waves. (a) Ion and electron number density. (b) lon energy spectrogram, and the solid line denotes the $\boldsymbol{E} \times \boldsymbol{B}$ drift energy $W_{E}$. (c) lon pitch angle spectrogram for ions with $2.2 \mathrm{eV} \leq E_{i} \leq 153.4 \mathrm{eV}$. (d) Normalized difference between the parallel ion PSD (pitch angle, $\sim 0^{\circ}-20^{\circ}$ ) and perpendicular PSD (pitch angle, $\sim 80^{\circ}-100^{\circ}$ ). (e) Normalized difference between the antiparallel PSD (pitch angle, $\sim 160^{\circ}-180^{\circ}$ ) and perpendicular PSD (pitch angle, $\sim 80^{\circ}-100^{\circ}$ ). (f) The $\boldsymbol{E} \times \boldsymbol{B}$ drift velocity $V_{E}$. The vertical dashed lines in figures $(\mathrm{a})-(\mathrm{f})$ represent minimum $V_{E}$. All plasma data come from the burst mode data of FPI.

time interval. The wavenumbers in FAC are given as $k_{\perp 1} \simeq 1.4$ $\times 10^{-3} \pm 0.3 \times 10^{-3} \mathrm{~km}^{-1}, \quad k_{\perp 2} \simeq 3.65 \times 10^{-4} \pm 0.05 \times 10^{-4} \mathrm{~km}^{-1}$, and $k_{\|} \simeq-2.45 \times 10^{-3} \pm 0.05 \times 10^{-3} \mathrm{~km}^{-1}$ by using the phase difference method ${ }^{40}$ for the magnetic envelop in one wave period during 20:39:39UT - 20:39:44UT. Since $\left(\lambda_{i} k_{\|}, \rho_{i} k_{\perp}, \rho_{s} k_{\perp}\right) \ll 1$, both the polarization and diamagnetic velocity drifts weakly affect the cold ion drift.

Previous statistical surveys have shown that $\mathrm{H}^{+}$-band EMIC waves are common in the dayside region of the outer magnetosphere. ${ }^{41,42}$ Also, highly disturbed geomagnetic conditions can yield high occurrence rates of EMIC waves in the afternoon sector, and strong dynamic pressure in the solar wind can yield high occurrence rates in the dayside outer magnetosphere. Considering that the duration of these waves is usually a few minutes to a few hours, ${ }^{41,42}$ therefore, the EMIC wave-induced cold ion modulation may frequently arise in the outer magnetosphere. However, the identification of these phenomena requires plasma measurements of high-temporal resolution, and the MMS spacecraft in the burst mode can make such observations possible.

This paper also identifies the modulation of ionospheric outflow cold ions by Pc5 ULF waves. This mechanism results in the modulation of cold ions at a timescale of $\sim 5 \mathrm{~min}$ in the ion energy spectrogram, and our results are consistent with the recent results in Refs. 20 and 21. Besides cold ions modulated by ULF waves and EMIC waves, Toledo-Redondo et al. ${ }^{43}$ recently proposed that the cold ion density exhibits a periodic fluctuation due to wake electric fields. This 


\section{E. AT DIFFERENT DIRECTIONS DURING BURST TIME INTERVAL}

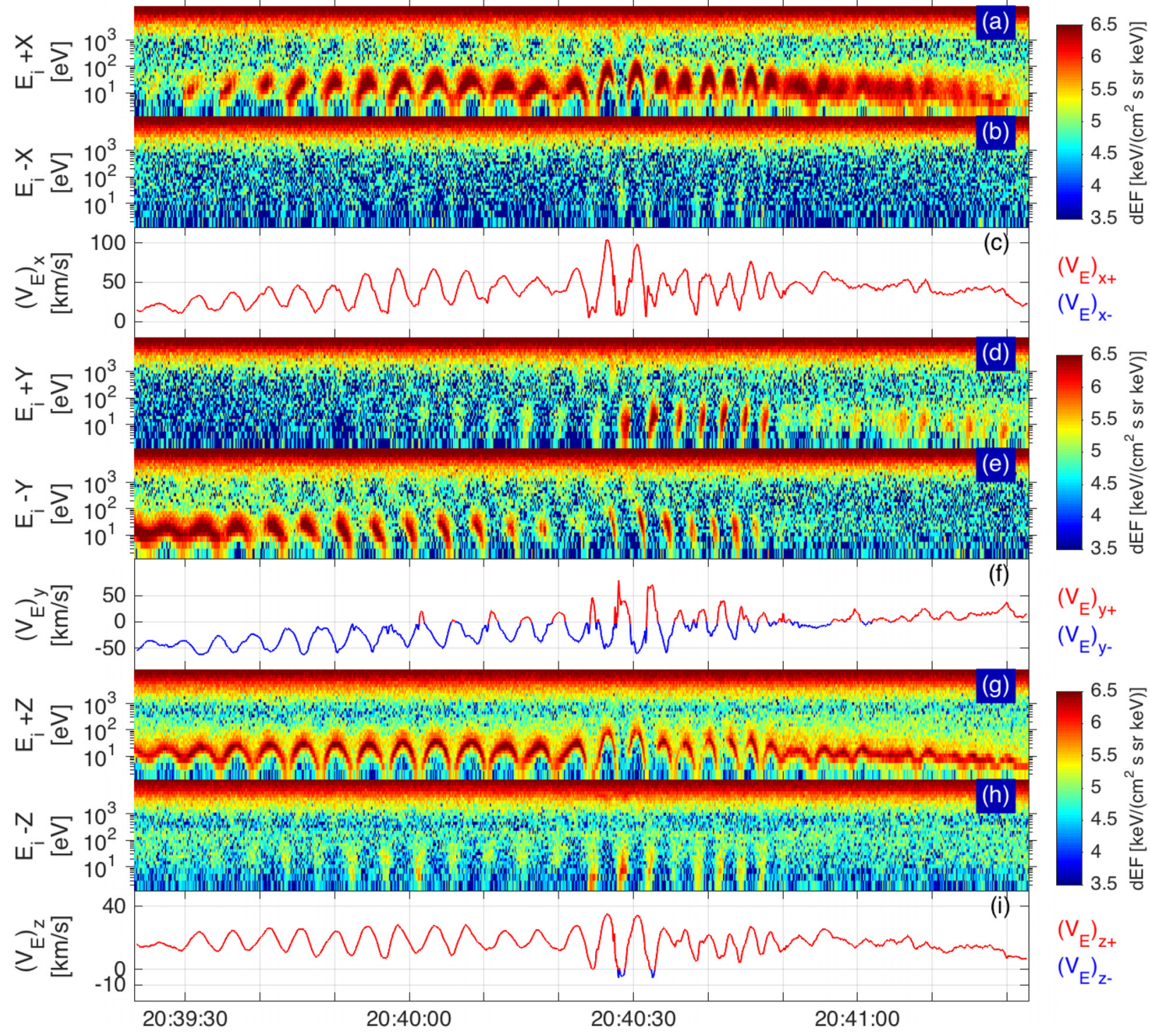

FIG. 6. Ion energy spectra $E_{i}$ at different directions during the burst time interval. (a) and (b) $E_{i}$ near $+x$ and $-x$ directions in DBCS. (d) and (e) $E_{i}$ near $+y$ and $-y$ directions in DBCS. (g) and (h) $E_{i}$ near $+z$ and $-z$ directions in DBCS. Drift velocities of electric field $V_{E}$ at different directions in GSE coordinates: (c) $x$, (f) $y$, and (i) $z$. The red and blue lines in panels (c), (f), and (i) represent the velocity along and against each axis.

modulation period is approximately $5 \mathrm{~s}$, that is, a quarter of the MMS spin period of $\sim 20 \mathrm{~s}$. In order to explore the difference between shorttimescale cold ion modulations by EMIC waves and by wake electric fields, Fig. 7 compares the detailed plasma and electromagnetic distributions in the EMIC wave-induced event and in wake electric fieldinduced events.

Figure 7(a) presents another event of cold ions modulated by EMIC waves, labeled as EMIC Event II. The timescale in this event is about $2 \mathrm{~s}$, which is different from the timescale $\sim 5 \mathrm{~s}$ in the cold ion event in Sec. III. It clearly shows that the EMIC wave determines the timescale of the variance in the cold ion energy spectrogram. Figures 7(b) and 7(c) give two wake electric field events analyzed in the study by Toledo-Redondo et al. ${ }^{43}$ In Wake Event I [Fig. 7(b)], wake electric fields (i.e., the periodic spikes in $E_{x}$ and $E_{y}$ distributions) arise when the Active Spacecraft Potential Control (ASPOC) instrument is not in operation. In Wake Event II [Fig. 7(c)] where the ASPOC is on, wake electric fields appear. ${ }^{43}$ It should be noted that for a medium cold ion density (several particles in $\mathrm{cm}^{-3}$ ), wake electric fields will be removed as the ASPOC instrument is in operation. ${ }^{43}$

Comparing EMIC wave-induced events in Figs. 4, 5, and 7(a) to weak electric field-induced events in Figs. 7(b) and 7(c), we can see many differences between these two kinds of cold ion modulations. 

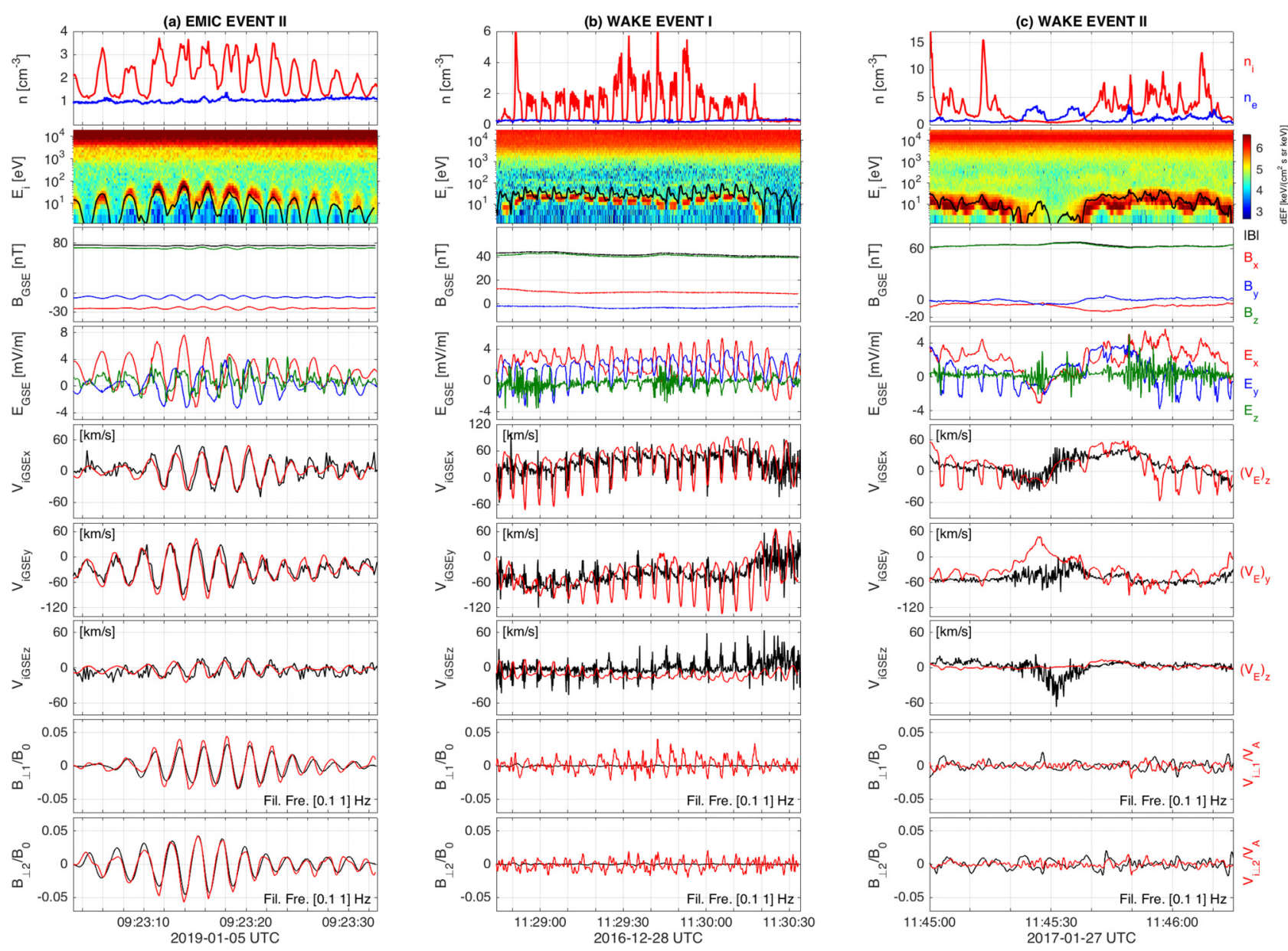

FIG. 7. The cold ion modulation by EMIC waves VS. by wake electric fields. (a) EMIC wave-modulated cold ion event on 5 January 2019, labeled as EMIC Event II. (b) Wake electric field-modulated cold ion event on 28 December 2016, labeled as Wake Event I, where the ASPOC instrument is not in operation. (c) Wake electric field-modulated cold ion event on 27 January 2017, labeled as Wake Event II, where the ASPOC instrument is in operation. From top to bottom panels, ion and electron densities (top panels), ion energy spectrogram (second panels), the magnetic field in GSE coordinates, the total magnetic field (third panels), the electric field in GSE coordinates (fourth panels), the

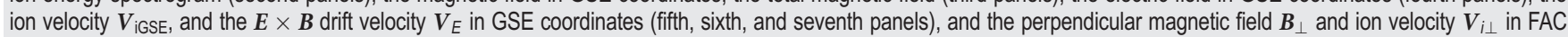
coordinates (eighth and bottom panels). $\boldsymbol{B}_{\perp}$ and $\boldsymbol{V}_{i \perp}$ are filtered in the range of $0.1 \mathrm{~Hz}-1 \mathrm{~Hz}$. The solid lines in the second row denote the $\boldsymbol{E} \times \boldsymbol{B}$ drift energy $\boldsymbol{W}_{E}$.

First, the magnetic fields behave sinusoidal/cosinusoidal fluctuations in EMIC wave-induced events, but wake electric field-induced events have no magnetic fluctuations. Second, both electric fluctuations $E_{x}$ and $E_{y}$ have a sinusoidal/cosinusoidal envelop in EMIC waveinduced events, but in wake electric field-induced events, $E_{x}$ and $E_{y}$ are spike-like and anti-correlated. Moreover, since our two EMIC wave-induced events contain medium cold ion densities $\left(\$ 5 \mathrm{~cm}^{-3}\right)$ and the ASPOC instrument is on, wake electric fields can be canceled out. ${ }^{43}$ Third, in EMIC wave-induced events, ion velocity fluctuations are in accord with the $\boldsymbol{E} \times \boldsymbol{B}$ drift velocity, but the measured ion velocities deviate from the $\boldsymbol{E} \times \boldsymbol{B}$ drift velocity in wake electric field-induced events. Fourth, in EMIC wave-induced events, the relationship between magnetic fluctuations and velocity fluctuations is consistent with the theoretical prediction, ${ }^{37,38}$ i.e., $\boldsymbol{B}_{\perp} / B_{0} \simeq \boldsymbol{V}_{i \perp} / V_{A}$, but this relationship does not exist in wake electric field-induced events.
Finally, based on the unidirectional propagation of EMIC waves antiparallel to the magnetic field, we propose that these waves are not locally generated. This conclusion is supported by the kinetic instability analysis. To distinguish the cold and hot particle components in our event, we use the following procedures: based on the maximum ion density near $5 \mathrm{~cm}^{-3}$ as shown in Fig. 5, the ambient ion number density is assumed as $n_{\mathrm{i}}=5 \mathrm{~cm}^{-3}$. Suppose that the ion population is composed of the hot component $\left(E_{i} \gtrsim 160 \mathrm{eV}\right)$ and cold component $\left(E_{i} \lesssim 160 \mathrm{eV}\right)$. The plasma parameters of hot ions are thus obtained by averaging the part-moments data from FPI measurements: $n_{\mathrm{i} 1}=0.53 \mathrm{~cm}^{-3}, T_{\mathrm{i} \| 1}=5.9 \mathrm{keV}$, and $T_{\mathrm{i} \perp 1}=7.7 \mathrm{keV}$. For cold ions, the number density is given as $n_{\mathrm{i} 2}=n_{\mathrm{i}}-n_{\mathrm{i} 1}=4.47 \mathrm{~cm}^{-3}$, and the temperature is assumed as $T_{\mathrm{i} \| 2}=T_{\mathrm{i} \perp 2}=1 \mathrm{eV}$. Similar to ions, the electron population is assumed to be contributed by hot and cold components. The averaged plasma parameters of hot electrons are directly given by FPI measurements: $n_{\mathrm{e} 1}=1.06 \mathrm{~cm}^{-3}, T_{\mathrm{e} \| 1}=368 \mathrm{eV}$, and 
$T_{\mathrm{e} \perp 1}=326 \mathrm{eV}$. For the cold electron population, we assume the isotropic temperature $T_{\mathrm{e} \| 2}=T_{\mathrm{e} \perp 2}=0.001 \mathrm{eV}$, and the number density is obtained as $n_{\mathrm{e} 2}=n_{\mathrm{i}}-n_{\mathrm{e} 1}=3.94 \mathrm{~cm}^{-3}$ based on the quasineutrality condition. Using these plasma parameters, we find that the temperature anisotropy $\left(T_{\mathrm{i} \perp 1}>T_{\mathrm{i} \| 1}\right)$ of hot ions induces unstable EMIC waves with the maximum growth rate near $0.0027 \mathrm{~s}^{-1}$. However, this growth rate is too weak to result in an effective amplification of EMIC waves. Note that this result is found to be almost independent of the cold ion and electron temperatures. The source region of these EMIC waves may be off-equator magnetic field minimum in the Earth's outer magnetosphere. ${ }^{44}$ After the waves escape from the source region, they can continually interact with cold ions along the propagation trajectory. Since the source of large-amplitude EMIC waves is still not fully explored, we will study this problem in the future.

\section{ACKNOWLEDGMENTS}

This work was supported by the NNSFC under Grant Nos. 41974203, 41531071, 11673069, and 11761131007. M.W.D. was supported by the NNSFC under Grant Nos. 41874193 and 41574155, the NERC under Grant No. NE/H004076/1, and by a STFC in-house research grant. C.H. was supported by the Open Fund of Science and Technology on Reliability and Environmental Engineering Laboratory. We thank the MMS team for data access and support, and the data are available at https://lasp.colorado.edu/mms/sdc/public/. The authors also thank Dr. Wenya Li for helpful discussions on the identification of EMIC waves from wake electric fields.

\section{REFERENCES}

${ }^{1}$ M. André and C. M. Cully, "Low-energy ions: A previously hidden solar system particle population," Geophys. Res. Lett. 39, L03101, https://doi.org/10.1029/ 2011GL050242 (2012).

${ }^{2}$ C. R. Chappell, T. E. Moore, and J. H. Waite, Jr., "The ionosphere as a fully adequate source of plasma for the Earth's magnetosphere," J. Geophys. Res. 92(A6), 5896-5910, https://doi.org/10.1029/JA092iA06p05896 (1987).

${ }^{3}$ A. W. Yau and M. André, "Sources of ion outflow in the high latitude ionosphere," Space Sci. Rev. 80(1-2), 1-25 (1997).

${ }^{4}$ M. O. Chandler and T. E. Moore, "Observations of the geopause at the equatorial magnetopause: Density and temperature," Geophys. Res. Lett. 30(16), 1869, https://doi.org/10.1029/2003GL017611 (2003).

${ }^{5} \mathrm{~J}$. H. Lee and V. Angelopoulos, "On the presence and properties of cold ions near Earth's equatorial magnetosphere,” J. Geophys. Res. 119(3), 1749-1770, https://doi.org/10.1002/2013JA019305 (2014).

${ }^{6} \mathrm{M}$. André, K. Li, and A. I. Eriksson, "Outflow of low-energy ions and the solar cycle," J. Geophys. Res. 120(2), 1072-1085, https://doi.org/10.1002/ 2014JA020714 (2015).

${ }^{7}$ Y. Xu, H. S. Fu, C. Norgren, S. Toledo-Redondo, C. M. Liu, and X. C. Dong, "Ionospheric cold ions detected by MMS behind dipolarization fronts," Geophys. Res. Lett. 46(14), 7883-7892, https://doi.org/10.1029/2019GL083885 (2019).

${ }^{8}$ M. André, A. Vaivads, Y. V. Khotyaintsev, T. Laitinen, H. Nilsson, G. Stenberg, A. Fazakerley, and J. G. Trotignon, "Magnetic reconnection and cold plasma at the magnetopause," Geophys. Res. Lett. 37(22), L22108, https:// doi.org/10.1029/2010GL044611 (2010).

${ }^{9}$ A. Divin, Y. V. Khotyaintsev, A. Vaivads, M. André, S. Toledo-Redondo, S, Markidis, and G. Lapenta, "Three-scale structure of diffusion region in the presence of cold ions," J. Geophys. Res. 121(12), 12001-12013, https://doi.org/ 10.1002/2016JA023606 (2016).

${ }^{10}$ S. Toledo-Redondo, M. André, A. Vaivads, Y. V. Khotyaintsev, B. Lavraud, D. B. Graham, A. Divin, and N. Aunai, "Cold ion heating at the dayside magnetopause during magnetic reconnection," Geophys. Res. Lett. 43(1), 58-66, https://doi.org/10.1002/2015GL067187 (2016).

${ }^{11}$ S. Toledo-Redondo, M. André, Y. V. Khotyaintsev, A. Vaivads, A. Walsh, W. Li, D. B. Graham, B. Lavraud, A. Masson, N. Aunai, A. Divin, J. Dargent, S. Fuselier, D. J. Gershman, J. Dorelli, B. Giles, L. Avanov, C. Pollock, Y. Saito, T. E. Moore, V. Coffey, M. O. Chandler, P. Lindqvist, R. Torbert, and C. T Russell, "Cold ion demagnetization near the X-line of magnetic reconnection," Geophys. Res. Lett. 43(13), 6759-6767, https://doi.org/10.1002/2016GL069877 (2016).

${ }^{12}$ S. Toledo-Redondo, M. André, Y. V. Khotyaintsev, B. Lavraud, A. Vaivads, D. B. Graham, W. Li, D. Perrone, S. Fuselier, D. J. Gershman, N. Aunai, J. Dargent, B. O. Le Contel, P. Lindqvist, R. E. Ergun, C. T Russell, and J. L. Burch, "Energy budget and mechanisms of cold ion heating in asymmetric magnetic reconnection," J. Geophys. Res. 122(9), 9396-9413, https://doi.org/ 10.1002/2017JA024553 (2017).

${ }^{13}$ S. Toledo-Redondo, J. Dargent, N. Aunai, B. Lavraud, M. André, W. Li, B. Giles, P. Lindqvist, R. E. Ergun, C. T. Russel, and J. L. Burch, "Perpendicular current reduction caused by cold ions of ionospheric origin in magnetic reconnection at the magnetopause: Particle-in-cell simulations and spacecraft observations," Geophys. Res. Lett. 45(19), 10033-10042, https://doi.org/10.1029/ 2018GL079051 (2018).

${ }^{14}$ W. Y. Li, M. André, Y. V. Khotyaintsev, A. Vaivads, S. A. Fuselier, D. B. Graham, S. Toledo-Redondo, B. Lavraud, D. L. Turner, C. Norgren, B. B. Tang, C. Wang, P. A. Lindqvist, D. T. Young, M. Chandler, B. Giles, C. Pollock, R. Ergun, C. T. Russell, R. Torbert, T. Moore, and J. Burch, "Cold ionospheric ions in the magnetic reconnection outflow region," J. Geophys. Res. 122(10), 10194-10202, https://doi.org/10.1002/2017JA024287 (2017).

${ }^{15}$ J. Dargent, N. Aunai, B. Lavraud, S. Toledo-Redondo, M. A. Shay, P. A. Cassak, and K. Malakit, "Kinetic simulation of asymmetric magnetic reconnection with cold ions," J. Geophys. Res. 122(5), 5290-5306, https://doi.org/10.1002/ 2016JA023831 (2017).

${ }^{16}$ J. Dargent, N. Aunai, B. Lavraud, S. Toledo-Redondo, and F. Califano, "Signatures of cold ions in a kinetic simulation of the reconnecting magnetopause,” J. Geophys. Res. 124(4), 2497-2514, https://doi.org/10.1029/ 2018JA026343 (2019).

${ }^{17}$ S.Toledo-Redondo, A. Vaivads, M. André, and Y. V. Khotyaintsev, "Modification of the Hall physics in magnetic reconnection due to cold ions at the Earth's magnetopause," Geophys. Res. Lett. 42(15), 6146-6154, https:// doi.org/10.1002/2015GL065129 (2015).

${ }^{18}$ M. André, W. Li, S. Toledo-Redondo, Y. V. Khotyaintsev, A. Vaivads, D. B. Graham, C. Norgren, J. Burch, P. A. Lindqvist, G. Marklund, G. Ergun, R. Torbert, W. Magnes, C. T. Russell, B. Giles, T. E. Moore, M. O. Chandler, C. Pollock, D. T. Young, L. A. Avanov, J. C. Dorelli, D. J. Gershman, W. R. Paterson, B. Lavraud, and Y. Saito, "Magnetic reconnection and modification of the Hall physics due to cold ions at the magnetopause," Geophys. Res. Lett. 43(13), 6705-6712, https://doi.org/10.1002/2016GL069665 (2016).

${ }^{19} \mathrm{M}$. Hirahara, K. Seki, Y. Saito, and T. Mukai, "Periodic emergence of multicomposition cold ions modulated by geomagnetic field line oscillations in the nearEarth magnetosphere," J. Geophys. Res. 109(A3), A03211, https://doi.org/ 10.1029/2003JA010141 (2004).

${ }^{20}$ B. Li, D. S. Han, Z. J. Hu, H. Q. Hu, J. J. Liu, L. Dai, H. Liu, C. P. Escoubet, M. W. Dunlop, R. E. Ergun, P. A. Lindqvist, R. B. Torbert, and C. T. Russell, "Magnetospheric multiscale observations of ULF waves and correlated lowenergy ion monoenergetic acceleration," J. Geophys. Res. 124(4), 2788-2794, https://doi.org/10.1029/2018JA026372 (2019).

${ }^{21}$ Z. Y. Liu, Q. G. Zong, X. Z. Zhou, Y. X. Hao, A. W. Yau, H. Zhang, X. R. Chen, S. Y. Fu, C. J. Pollock, G. Le, R. R. Ergun, and P. A. Lindqvist, "waves modulating and acting as mass spectrometer for dayside ionospheric outflow ions," Geophys. Res. Lett. 46, 8633-8642, https://doi.org/10.1029/2019GL083849 (2019).

${ }^{22}$ T. Sakurai, Y. Tonegawa, T. Kitagawa, M. Nowada, A. Yamawaki, T. Mukai, S. Kokubun, T. Yamamoto, and K. Tsuruda, "Double-frequency oscillations of low energy plasma associated with transverse Pc 5 pulsations: GEOTAIL satellite observations," Earth Planets Space 51(1), 43-53 (1999).

${ }^{23}$ D. J. Southwood and M. G. Kivelson, "Charged particle behavior in low-frequency geomagnetic pulsations 1. Transverse waves,” J. Geophys. Res. 86(A7), 5643-5655, https://doi.org/10.1029/JA086iA07p05643 (1981). 
${ }^{24}$ M. Hartinger, V. Angelopoulos, M. B. Moldwin, Y. Nishimura, D. L. Turner, K. H. Glassmeier, M. G. Kivelson, J. Matzka, and C. Stolle, "Observations of a Pc5 global (cavity/waveguide) mode outside the plasmasphere by THEMIS," J. Geophys. Res. 117(A6), A06202, https://doi.org/10.1029/2011JA017266 (2012).

${ }^{25}$ L. Dai, K. Takahashi, J. R. Wygant, L. Chen, J. Bonnell, C. A. Cattell, S. Thaller, C. Kletzing, C. W. Smith, R. J. MacDowall, D. N. Baker, J. B. Blake, J. Fennel, S. Claudepierre, H. O. Funsten, G. D. Reeves, and H. E. Spence, "Excitation of poloidal standing Alfvén waves through drift resonance wave-particle interaction," Geophys. Res. Lett. 40(16), 4127-4132, https://doi.org/10.1002/ $\operatorname{grl} .50800$ (2013).

${ }^{26} \mathrm{~L}$. Dai, K. Takahashi, R. Lysak, C. Wang, J. R. Wygant, C. Kletzing, J. Bonnell, C. A. Cattell, C. W. Smith, R. J. MacDowall, C. Thaller, A. Breneman, X. Tang, X. Tao, and L. Chen, "Storm time occurrence and spatial distribution of Pc4 poloidal ULF waves in the inner magnetosphere: A van Allen probes statistical study," J. Geophys. Res. 120(6), 4748-4762, https://doi.org/10.1002/2015JA021134 (2015).

${ }^{27}$ Z. Su, H. Zhu, F. Xiao, Q. G. Zong, X. Z. Zhou, H. Zheng, Y. Wang, S. Wang, Y. X. Hao, Z. Gao, Z. He, D. N. Baker, H. E. Spence, G. D. Reeves, J. B. Blake, and J. R. Wygant, "Ultra-low-frequency wave-driven diffusion of radiation belt relativistic electrons," Nat. Commun. 6, 10096 (2015).

${ }^{28}$ G. Le, P. J. Chi, R. J. Strangeway, C. T. Russell, J. A. Slavin, K. Takahashi, H. J. Singer, B. J. Anderson, K. Bromund, D. Fischer, E. L. Kepko, W. Magnes, R. Nakamura, F. Plaschke, and R. B. Torbert, "Global observations of magnetospheric high-m poloidal waves during the 22 June 2015 magnetic storm," Geophys. Res. Lett. 44(8), 3456-3464, https://doi.org/10.1002/2017GL073048 (2017).

${ }^{29}$ Q. G. Zong, X. Z. Zhou, X. Li, P. Song, S. Y. Fu, D. N. Baker, Z. Y. Pu, T. A. Fritz, P. Daly, A. Balogh, and H. Réme, "Ultralow frequency modulation of energetic particles in the dayside magnetosphere," Geophys. Res. Lett. 34(12), L12105, https://doi.org/10.1029/2007GL029915 (2007).

${ }^{30}$ Q. G. Zong, Y. F. Wang, H. Zhang, S. Y. Fu, H. Zhang, C. R. Wang, C. J. Yuan, and I. Vogiatzis, "Fast acceleration of inner magnetospheric hydrogen and oxygen ions by shock induced ULF waves," J. Geophys. Res. 117(A11), A11206, https://doi.org/10.1029/2012JA018024 (2012).

${ }^{31} \mathrm{Q}$. Zong, R. Rankin, and X. Zhou, "The interaction of ultra-low-frequency pc35 waves with charged particles in Earth's magnetosphere," Rev. Mod. Plasma Phys. 1(1), 10 (2017).

${ }^{32}$ C. Pollock, T. Moore, A. Jacques, J. Burch, U. Gliese, Y. Saito, T. Omoto, L. Avanov, A. Barrie, V. Coffey, J. Dorelli, D. Gershman, B. Giles, T. Rosnack, C. Salo, S. Yokota, M. Adrian, C. Aoustin, C. Auletti, S. Aung, V. Bigio, N. Cao, M. Chandler, D. Chornay, K. Christian, G. Clark, G. Collinson, T. Corris, A. De Los Santos, R. Devlin, T. Diaz, T. Dickerson, C. Dickson, A. Diekmann, F. Diggs, C. Duncan, A. Figueroa-Vinas, C. Firman, M. Freeman, N. Galassi, K. Garcia, G. Goodhart, D. Guererro, J. Hageman, J. Hanley, E. Hemminger, M. Holland, M. Hutchins, M. Hutchins, T. James, W. Jones, S. Kreisler, J. Kujawski, V. Lavu, J. Lobell, E. LeCompte, A. Lukemire, E. MacDonald, T. Mariano, T. Mukai, K. Narayanan, Q. Nguyan, M. Onizuka, W. Paterson, S. Persyn, B. Piepgrass, F. Cheney, A. Rager, T. Raghuram, A. Ramil, L. Reichenthal, H. Rodriguez, J. Rouzaud, A. Rucker, Y. Saito, M. Samara, J.-A. Sauvaud, D. Schuster, M. Shappirio, K. Shelton, D. Sher, D. Smith, K. Smith, S. Smith, D. Steinfeld, R. Szymkiewicz, K. Tanimoto, J. Taylor, C. Tucker, K. Tull, A. Uhl, J. Vloet, P. Walpole, S. Weidner, D. White, G. Winkert, P.-S. Yeh, and M. Zeuch, "Fast plasma investigation for magnetospheric multiscale," Space Sci. Rev. 199(1-4), 331-406 (2016).
${ }^{33}$ C. T. Russell, B. J. Anderson, W. Baumjohann, K. R. Bromund, D. Dearborn, D. Fischer, G. Le, H. K. Leinweber, D. Leneman, W. Magnes, J. D. Means, M. B. Moldwin, R. Nakamura, D. Pierce, F. Plaschke, K. M. Rowe, J. A. Slavin, R. J. Strangeway, R. Torbert, C. Hagen, I. Jernej, A. Valavanoglou, and I. Richter, "The magnetospheric multiscale magnetometers," Space Sci. Rev. 199(1-4), 189-256 (2016).

${ }^{34}$ R. E. Ergun, S. Tucker, J. Westfall, K. A. Goodrich, D. M. Malaspina, D. Summers, J. Wallace, M. Karlsson, J. Mack, N. Brennan, B. Pyke, P. Withnell, R. Torbert, J. Macri, D. Rau, I. Dors, J. Needell, P.-A. Lindqvist, G. Olsson, and C. M. Culley, "The axial double probe and fields signal processing for the MMS mission," Space Sci. Rev. 199(1-4), 167-188 (2016).

${ }^{35}$ P. A. Lindqvist, G. Olsson, R. B. Torbert, B. King, M. Granoff, D. Rau, G. Needell, S. Turco, I. Dors, P. Beckman, J. Macri, C. Frost, J. Salwen, A Eriksson, L. Åhlén, Y. V. Khotyaintsev, J. Porter, K. Lappalainen, R. E. Ergun, W. Wermeer, and S. Tucker, "The spin-plane double probe electric field instrument for MMS,” Space Sci. Rev. 199(1-4), 137-165 (2016).

${ }^{36}$ O. Santolík, M. Parrot, and F. Lefeuvre, "Singular value decomposition methods for wave propagation analysis," Radio Sci. 38(1), 1010, https://doi.org/ 10.1029/2000RS002523 (2003).

${ }^{37} \mathrm{~J}$. Zhao, "Dispersion relations and polarizations of low-frequency waves in twofluid plasmas," Phys. Plasmas 22(4), 042115 (2015).

${ }^{38}$ J. Zhao, T. Wang, D. B. Graham, J. He, W. Liu, W. M. Dunlop, and D. Wu, "Identification of the nature of electromagnetic waves near the protoncyclotron frequency in solar-terrestrial plasmas," APJ 890, 17 (2020).

${ }^{39} \mathrm{P}$. Welch, "The use of fast Fourier transform for the estimation of power spectra: A method based on time averaging over short, modified periodograms," IEEE Trans. Audio Electroacoust. 15(2), 70-73 (1967).

${ }^{40}$ D. J. Gershman, F. Adolfo, J. C. Dorelli, S. A. Boardsen, L. A. Avanov, P. M. Bellan, S. J. Schwartz, B. Lavraud, V. N. Coffey, M. O. Chandler, Y. Saito, W. R. Paterson, S. A. Fuselier, R. E. Ergun, R. J. Strangeway, C. T. Russell, L. Giles, C. L. Pollock, R. B. Torbert, and J. L. Burch, "Wave-particle energy exchange directly observed in a kinetic Alfvén-branch wave," Nat. Commun. 8(1), 1-10 (2017).

${ }^{41}$ R. C. Allen, J. C. Zhang, L. M. Kistler, H. E. Spence, R. L. Lin, B. Klecker, M. W. Dunlop, M. André, and V. K. Jordanova, "A statistical study of EMIC waves observed by cluster: 1. Wave properties,” J. Geophys. Res. 120(7), 5574-5592, https://doi.org/10.1002/2015JA021333 (2015).

${ }^{42}$ X. Y. Wang, S. Y. Huang, R. C. Allen, H. S. Fu, X. H. Deng, M. Zhou, J. L. Burch, and R. B. Torbert, "The occurrence and wave properties of EMIC waves observed by the magnetospheric multiscale (MMS) mission," J. Geophys. Res. 122(8), 8228-8240, https://doi.org/10.1002/2017JA024237 (2017).

${ }^{43}$ S. Toledo-Redondo, B. Lavraud, S. A. Fuselier, M. André, Y. V. Khotyaintsev, N. Nakamura, C. P. Escoubet, W. Y. Li, K. Torkar, F. Cipriani, A. C. Barrie, B. Giles, T. E. Moore, D. Gershman, P.-A. Lindqvist, R. E. Ergun, C. T. Russell, and J. L. Burch, "Electrostatic spacecraft potential structure and wake formation effects for characterization of cold ion beams in the Earth's magnetosphere," J. Geophys. Res. 124, 10048, https://doi.org/10.1029/2019JA027145 (2019).

${ }^{44}$ S. K. Vines, R. C. Allen, B. J. Anderson, M. J. Engebretson, S. A. Fuselier, C. T. Russell, R. J. Strangeway, R. E. Ergun, P. A. Lindqvist, R. B. Torbert, and J. L. Burch, "EMIC waves in the outer magnetosphere: Observations of an off-equator source region,” Geophys. Res. Lett. 46(11), 5707-5716, https://doi.org/ 10.1029/2019GL082152 (2019). 